\title{
CIANOBACTÉRIAS EM RESERVATÓRIOS DO ESTADO DE PERNAMBUCO: OCORRÊNCIA E TOXICIDADE
}

\author{
V. H. M. LIMA \\ Laboratório Central de Saúde Pública - Dr. Milton Bezerra Sobral (LACEN/PE) \\ victor.hg.ml@hotmail.com
}

Submetido 26/06/2016 - Aceito 23/06/2017

DOI: $10.15628 /$ holos.2017.4470

\section{RESUMO}

A qualidade da água dos reservatórios de abastecimento público do Estado de Pernambuco vem sendo comprometida, no que concerne a seu padrão de potabilidade, isto se deve ao intenso processo de eutrofização. Este processo de enriquecimento das águas prejudica os usos múltiplos dos reservatórios, principalmente pelo fato de propiciar o desenvolvimento de florações de cianobactérias potencialmente produtoras de cianotoxinas que podem afetar a saúde de muitos animais, inclusive do homem. Deste modo, o presente estudo teve como objetivo realizar o levantamento taxonômico das cianobactérias e determinar a concentração de cianotoxinas pelo método imunoenzimático (ELISA) nos reservatórios de Jucazinho e Carpina, situados no Agreste e na Zona da Mata Norte do Estado de Pernambuco, respectivamente. As amostras foram coletadas com frequência mensal, durante os meses de setembro a dezembro de 2014, na região limnética próximo ao ponto de captação dos reservatórios. Foi relatada a ocorrência de florações de cianobactérias potencialmente produtoras de cianotoxinas em amostras de água dos reservatórios estudados. Contudo, as concentrações de cianotoxinas em ambos os reservatórios ficaram abaixo dos valores máximos permissíveis estabelecidos na portaria MS 2.914/2011 Diante de tais resultados, a ocorrência de "blooms" tóxicos de cianobactérias nos reservatórios em estudo aponta um risco permanente de cianotoxinas e indica a necessidade da implementação de medidas de controle das florações, visando à melhoria da qualidade das águas.

PALAVRAS-CHAVE: reservatório, cianobactérias, cianotoxinas, saúde pública.

\section{CYANOBACTERIA IN RESERVOIRS IN THE STATE OF PERNAMBUCO: OCURRENCE AND TOXICITY}

\begin{abstract}
The quality and potability of water in public water supply reservoirs in the state of Pernambuco are being jeopardized by an intense eutrophication process. That enrichment of the waters puts at risk the multiple uses of the water as it propitiates the development of cyanobacteria blooms capable of producing cyanotoxins harmful to the health of many animals including man. This study set out to conduct a taxonomic survey of the cyanobacteria in the waters of the Jucazinho and Carpina reservoirs in the 'Agreste' and northern 'Zona da Mata' regions, respectively, in the state of Pernambuco and to determine cyanotoxin concentrations in them by enzyme-linked
\end{abstract}

immunosorbent assay (ELISA). Monthly samples were collected from September to December 2014 in the limnetic zone near to the point of catchment in the reservoirs. Cyanobacteria blooms were identified in the reservoir water samples that could potentially produce cyanotoxins. However the toxin concentrations in both reservoirs were below the maximum levels permitted in the respective Ministry of Health regulatory document MS 2.914/2011. The results indicate that the occurrence of toxic cyanobacteria blooms represent a permanent risk of cyanotoxins and the need to take steps to control the blooms and improve water quality.

KEYWORDS: reservoir, cyanobacteria, cyanotoxins, public health. 


\section{INTRODUÇÃO}

Perante o problema da falta de água no Brasil, tanto em qualidade como em quantidade, o país enfrenta problemas quanto à sua má distribuição e eutrofização dos corpos d'água. $O$ rápido crescimento da população, a formação de aglomerados urbanos e o aumento da produção agrícola e industrial resultaram no aumento da descarga de poluentes em corpos d'água, especialmente de matéria orgânica e nutrientes como nitrogênio e fósforo, tornando-os cada vez mais eutrofizados. Este fenômeno favorece a proliferação excessiva de cianobactérias potencialmente tóxicas em reservatórios utilizados para abastecimento público. Estes eventos têm sido cada vez mais frequentes, causando profundos impactos sociais, econômicos e ambientais (TUNDISI, 2008; DI BERNARDO et al., 2010).

As cianobactérias são organismos procarióticos, autotróficos, fotossintetizantes e fixadores de nitrogênio (MOLICA \& AZEVEDO, 2009). São normalmente unicelulares, mas é comum que cresçam em grandes colônias visíveis chamadas de florações ou "blooms" (CALIJURI et al., 2006). Essas florações podem apresentar gêneros potencialmente tóxicos, produtores de cianotoxinas, tendo efeitos neuro, hepato e dermatotóxicos em animais e também em seres humanos (CHEN et al., 2011; SANT'ANNA et al., 2006; CARNEIRO \& LEITE, 2008). As hepatotoxinas, principalmente microcistinas e cilindrospermopsina, são as causadoras mais comuns de intoxicações em seres humanos e em outros animais (MEREL et al., 2010).

No Brasil há ocorrência de cepas tóxicas de cianobactérias em reservatórios de abastecimento público, lagoas salobras e rios em vários Estados (AZEVEDO, 1998). O caso mais grave envolvendo a morte de seres humanos ficou conhecido como a "Síndrome da Hemodiálise" que ocorreu na cidade de Caruaru, em 1996, no nordeste do Brasil, em que mais de 70 pacientes de uma clínica de hemodiálise vieram a óbito devido à intoxicação por cianotoxinas (DÖRR et al., 2010).

Este fato impulsionou o estudo dos riscos impostos pela ocorrência de cianobactérias em corpos d'água utilizados para o abastecimento público e a criação de legislação específica para o aperfeiçoamento do controle da qualidade da água, incluindo o monitoramento de cianotoxinas. O Brasil foi o primeiro país do mundo a ter uma lei federal (Portaria no 518/2004 do Ministério da Saúde), atualizada pela Portaria no 2.914/2011 do Ministério da Saúde que estabelece os 
procedimentos e responsabilidades relativos ao controle e vigilância da qualidade da água para consumo humano e seu padrão de potabilidade (BRASIL, 2011).

Perante o problema da contaminação da água dos reservatórios de abastecimento público por cianobactérias, sendo este um dos fatores que influenciam nos padrões da qualidade da água potável, podendo gerar danos à saúde pública, portanto é necessário analisar a densidade de cianobactérias e a concentração de cianotoxinas nas águas de dois importantes reservatórios do Estado de Pernambuco, Jucazinho e Carpina.

\section{MATERIAIS E MÉTODOS}

\subsection{Caracterização da área de estudo}

Os reservatórios de Jucazinho e Carpina integram uma região com área de 5.947 km², localizado na porção nordeste do Estado de Pernambuco (Figura 1). Situam-se na bacia hidrográfica do rio Capibaribe.

O rio Capibaribe é barrado e forma o reservatório de Jucazinho no município de Surubim $\left(7^{\circ} 57^{\prime} 50^{\prime \prime} \mathrm{S}\right.$ e $\left.35^{\circ} 44^{\prime} 30^{\prime \prime} \mathrm{W}\right)$ a aproximadamente $135 \mathrm{~km}$ de sua nascente; aproximadamente $52 \mathrm{~km}$ a jusante, o rio é novamente barrado no município de Carpina, e forma o reservatório de Carpina $\left(7^{\circ} 53^{\prime} 677^{\prime \prime}\right.$ S e $35^{\circ} 20^{\prime} 278^{\prime \prime} \mathrm{W}$ ) (ANDRADE, 2002). A bacia está envolvida pelas isoeitas de $1.000 \mathrm{~mm}$, a leste, e $500 \mathrm{~mm}$, a oeste, a região apresenta predomínio do clima semiárido, tipo Dd, segundo a classificação de Thorntwaite. As chuvas se concentram de março a julho, com precipitação anual média de 657,3 mm e evaporação anual média de 2.200 mm (MIN-DNOCS, 1991).

O reservatório de Jucazinho possui capacidade de acumulação de $327.000 .000 \mathrm{~m}^{3} \mathrm{e}$ abastece a população das seguintes cidades e localidades do Agreste pernambucano: Casinhas, Frei Miguelinho, Salgadinho, Santa Maria do Cambucá, Surubim, Chéus, Vertente do Lério, Vertentes, Caruaru, Bezerros, Cumaru, Passira, Riacho das Almas e Bezerros beneficiando assim, uma população de mais de 350.000 habitantes (COMPESA, 2008). O reservatório de Carpina tem a capacidade de acumulação equivalente a $270.000 .000 \mathrm{~m}^{3}$, possui extensão de $7.557 \mathrm{~km}$, na Zona da Mata Norte de Pernambuco. O reservatório foi construído tendo por objetivo o controle das cheias do rio Capibaribe (SRHE, 2010). 

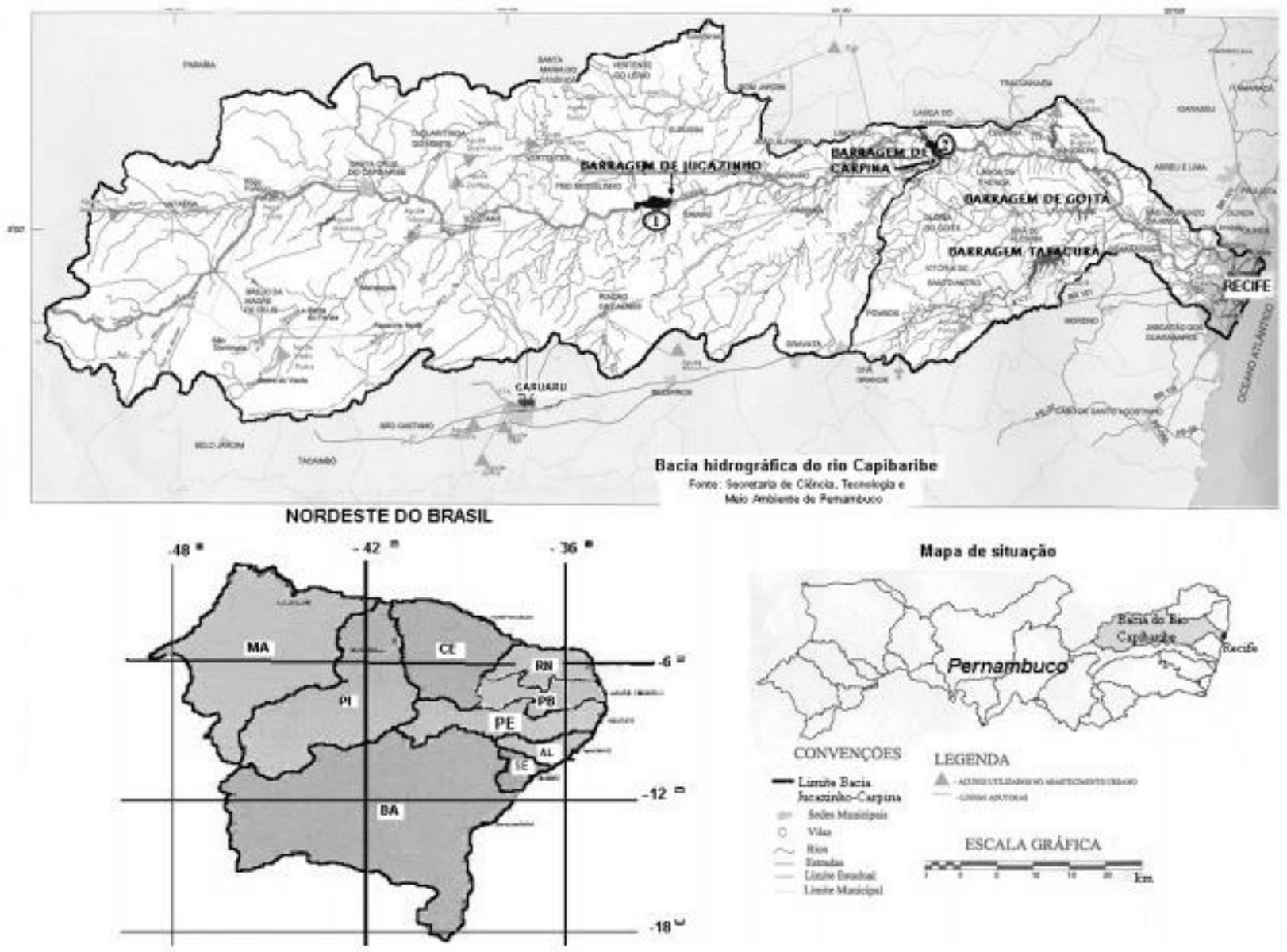

Figura 1. Localização dos reservatórios Jucazinho (1) e Carpina (2) na bacia do rio Capibaribe.

\subsection{Procedimento de coleta}

As amostras de água dos reservatórios de Jucazinho e Carpina foram coletados por técnicos das Gerências Regionais de Saúde (GERES) nos meses de setembro, outubro, novembro e dezembro de 2014, em um único local do reservatório próximo ao ponto de captação, na camada subsuperficial da coluna d'água (zona eufótica), $50 \mathrm{~cm}$ abaixo da superfície, com auxílio de uma garrafa de Van Dorn para obtenção de amostras para as análises qualiquantitativa de cianobactérias e detecção de cianotoxinas.

A variável meteorológica analisada durante o período de estudo foi a pluviosidade. Esta variável pode interferir na ocorrência de cianobactérias em cursos d'água. Os dados referentes à média de precipitação pluviométrica mensal foram obtidos pela Agência Pernambucana de Águas 
e Clima (APAC, 2014), enquanto que os dados de temperatura da água foram obtidos com o auxílio de uma sonda multiparâmetro.

As amostras para análise de cianobactérias foram acondicionadas em frascos identificados de polietileno com volume de $250 \mathrm{~mL}$ contendo $25 \mathrm{~mL}$ de solução de lugol acético, com concentração final de 1\%. Para análise de cianotoxinas, as amostras foram transferidas para recipientes de vidro na cor âmbar com volume de $1000 \mathrm{~mL}$ sem a presença de qualquer fixador (amostra viva). As amostras para análise de cianotoxinas foram identificadas e acondicionas em caixa térmica com baterias de gelo para transporte ao Laboratório Central de Saúde Pública - Dr. Milton Bezerra Sobral (LACEN/PE).

\subsection{Análise qualitativa de cianobactérias}

Para as análises qualitativas, as amostras foram homogeneizadas e colocadas em tubos de $50 \mathrm{~mL}$ com fundo cônico. Os tubos foram centrifugados por 20 minutos a $2.500 \mathrm{rpm}$, o sobrenadante foi retirado até o limite cônico com o auxílio de uma pipeta. Com o concentrado residual foram feitas lâminas para serem observadas em microscópio óptico dotado de retículo micrométrico. Para identificação taxonômica das cianobactérias, foi adotado o sistema de classificação proposto por Komárek e Anagnostidis (1986, 1999 e 2005). Os espécimes foram identificados sempre que possível em nível infragenético.

\subsection{Análise quantitativa de cianobactérias}

As amostras fixadas com lugol acético a $1 \%$ foram homogeneizadas e sedimentadas em cubetas de Utermöhl com volume de $5 \mathrm{~mL}$ por um período de 24 horas (UTERMÖHL, 1958). No dia seguinte, as amostras foram analisadas em microscópio invertido com contraste de fase e retículo de Whipple em objetiva de 40X. Os indivíduos foram contados por transectos até atingir, sempre que possível, 100 indivíduos da espécie predominante, buscando atingir um limite de confiança de 95\%, com erro inferior a 20\%, segundo a distribuição de Poisson (APHA, 2012). Após a contagem, foi realizado o cálculo do total de indivíduos de cada espécies, a partir da multiplicação da respectiva média de células pelo fator (F) de conversão do número de células contadas (CETESB, 
2005). O cálculo da densidade foi expresso em cel. $\mathrm{mL}^{-1}$ a partir da fórmula descrita na American Public Health Association - APHA (APHA, 2012).

O estudo quantitativo das cianobactérias foi baseado na portaria MS 2.914/2011 que dispõe sobre os procedimentos de controle e vigilância da qualidade da água para consumo humano e seu padrão de potabilidade. A frequência de ocorrência dos taxa foi determinada segundo Mateucci \& Colma (1982), que definem as seguintes faixas de classificação: muito frequente $(>70 \%)$, frequente $(\leq 70 \%$ e $>40 \%)$, pouco frequente $(\leq 40 \%$ e $>10 \%)$ e raro $(\leq 10 \%)$.

\subsection{Determinação da concentração de cianotoxinas}

Para a análise foi utilizada uma alíquota de $5 \mathrm{~mL}$ da amostra, em seguida foi realizado o congelamento e descongelamento por três vezes consecutivas com o objetivo de facilitar a lise das células. A determinação de cianotoxinas foi realizada com o kit comercial ELISA da Abraxis , Warminster, PA, USA, seguindo o protocolo do fabricante. Foi analisada a toxicidade das amostras para as toxinas microcistinas, saxitoxina e cilindrospermopsinas. A detecção limite para as toxinas por ELISA foi $0,1 \mathrm{ppb}, 0,02 \mathrm{ppb}$ e 0,1 ppb, respectivamente. Os padrões, controles positivo e negativo foram fornecidos no kit. O método consiste em anticorpos específicos fixados nas paredes dos poços que se ligam a toxina presente na amostra, e após sucessivas etapas ocorre uma reação de cor. A concentração da toxina é inversamente proporcional à intensidade da cor desenvolvida na reação com o substrato. A leitura das amostras foi realizada em um leitor de placa ELISA para medir a absorbância com um comprimento de onda de $450 \mathrm{~nm}$. Os experimentos foram realizados em triplicada e seus resultados foram impressos.

\section{RESULTADOS E DISCUSSÕES}

\subsection{Variável meteorológica}

A variável meteorológica considerada nesse estudo foi a pluviosidade. No Agreste e Zona da Mata pernambucana há dois períodos distintos de precipitação, o período das águas que ocorre entre os meses de março a julho, caracterizando a estação das chuvas e o período seco, estação em que as precipitações são menos intensas, o qual se estende entre os meses de agosto a fevereiro. O mês com maior precipitação nos reservatórios de Jucazinho e Carpina foi em 
setembro $(25 \mathrm{~mm})$ e $(36 \mathrm{~mm})$ e a menor precipitação ocorreu nos meses de novembro (14 $\mathrm{mm})$ e dezembro $(18 \mathrm{~mm})$, respectivamente. A precipitação registrada no período de estudo está representada na figura 2 .

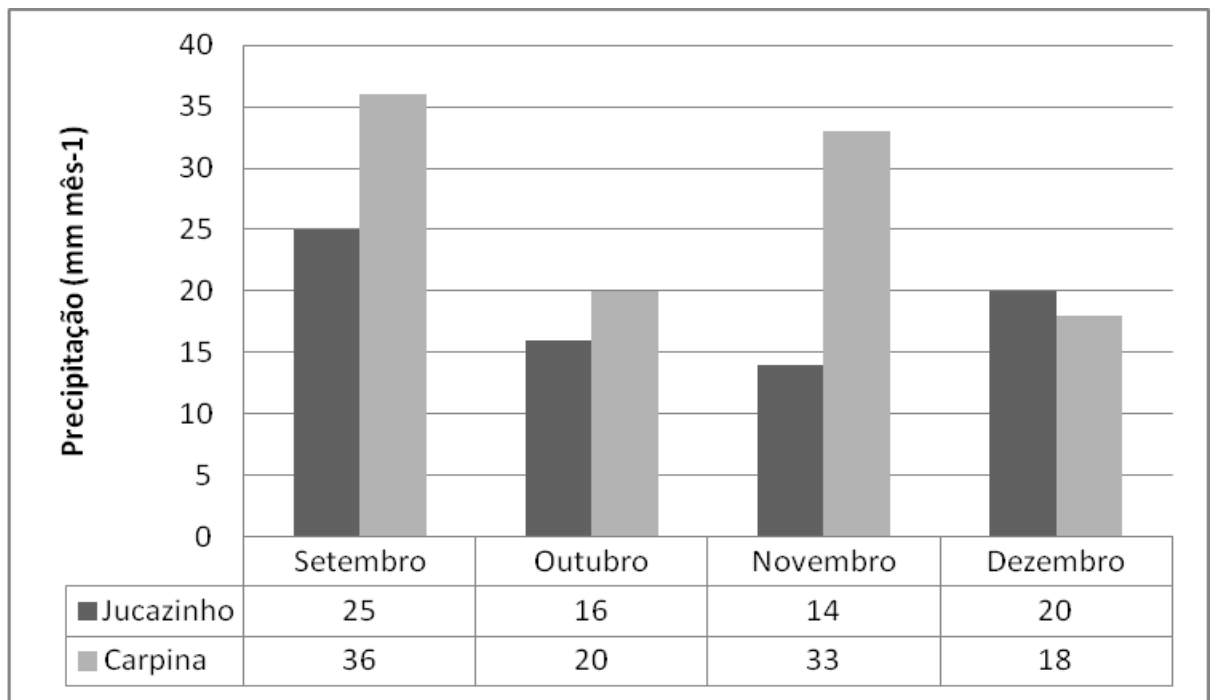

Figura 2: Precipitação pluviométrica $\left(\mathrm{mm} \mathrm{mês}^{-1}\right)$ ocorrida nos reservatório de Jucazinho e Carpina entre os meses de setembro a dezembro/2014.

A precipitação é um fator essencial na determinação da densidade e da composição taxonômica das microalgas e cianobactérias. De acordo com Tundisi et al., (2008), o aumento do volume de água, não mantém comunidades densas de fitoplâncton, porque esses organismos são levados pelo fluxo da água. As cianobactérias, geralmente, não se desenvolvem em reservatórios que possuem curto tempo de retenção (CHORUS E BARTRAM, 1999).

A figura 3 apresenta a variação térmica da água durante os meses de estudo. As variações de temperatura foram muito semelhantes entre os reservatórios. Isso pode ser explicado devido ao tempo de retenção da água nos mananciais, apresentando características lênticas. De acordo com Figueredo \& Gani (2001), oscilações na temperatura em ambientes aquáticos tropicais não são muito altas. Trabalhos realizados em ambientes aquáticos tropicais geralmente encontram uma variação sazonal de pequena amplitude na temperatura da água (MAIA-BARBOSA et al., 2008) 


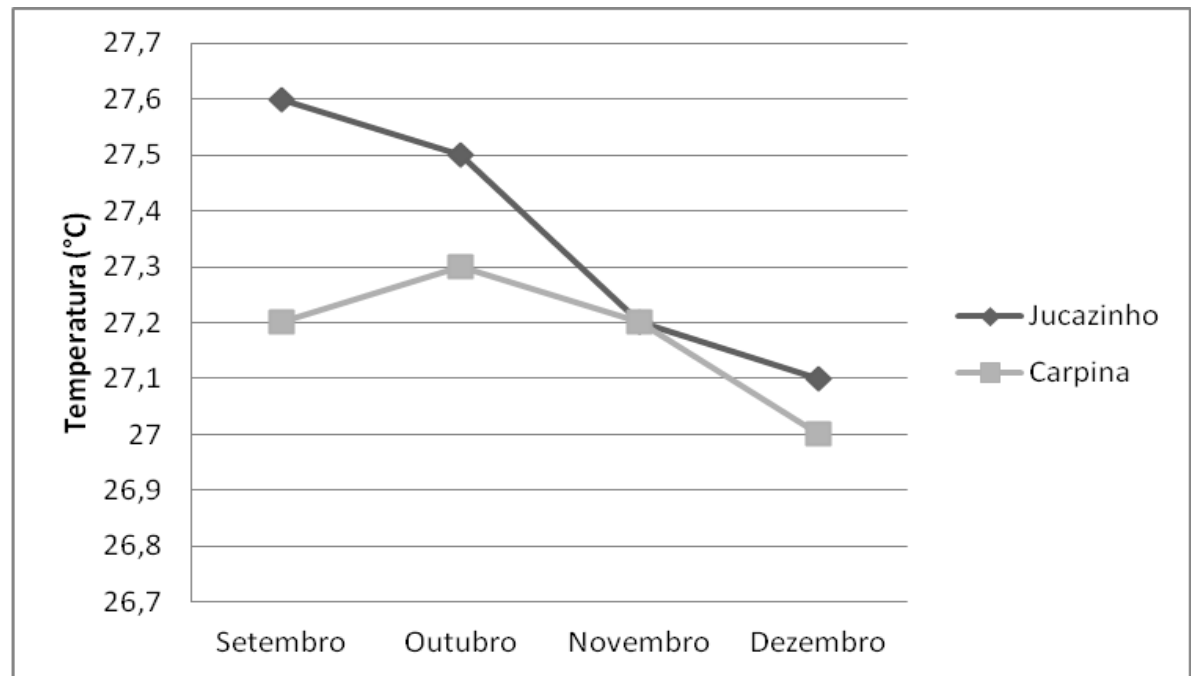

Figura 3: Variação da temperatura $\left({ }^{\circ} \mathrm{C}\right)$ da água nos reservatórios de Jucazinho e Carpina.

\subsection{Análise qualiquantitativa de cianobactérias}

A partir das análises qualitativas das amostras dos reservatórios de Jucazinho e Carpina, observaram-se 11 taxa de cianobactérias: Planktothrix sp., Synechocystis sp., Geitlerinema amphibium, Aphanocapsa sp., Raphidiopsis mediterranea, R. curvata, Microcystis sp., Pseudoanabaena sp., Sphaerospermopsis aphanizomenoides, Merismopedia sp. e Cylindrospermopsis raciborskii (Tabela 1 e 2). Dentre os espécimes identificados, apenas Merismopedia sp. não é citado na literatura como potencialmente produtor de cianotoxinas. Em Pernambuco, Bittencourt-Oliveira et al., (2014) observaram nos reservatórios do Estado a ocorrência dos seguintes gêneros: Microcystis sp., Planktothrix sp., Cylindrospermopsis sp., Geitlerinema sp., Sphaerospermopsis sp. e Merismopedia sp. A ocorrência de florações de cianobactérias em corpos d'água para abastecimento público tem sido cada vez mais frequente, favorecido pela situação do ambiente, que se encontra eutrofizado, rico em nutrientes, como fósforo e nitrogênio (BARRETO et al., 2013). O clima da região nordeste também é um fator que estimula o desenvolvimento das cianobactérias.

Quanto à frequência de ocorrência, no reservatório de Jucazinho dos 8 taxa identificados $50 \%$ foram considerados muito frequentes, $25 \%$ frequentes e $25 \%$ pouco frequentes (Tabela 1 ). No reservatório de Carpina, dos 10 taxa identificados 60\% foram considerados muito frequentes, $10 \%$ frequentes e $30 \%$ pouco frequentes (Tabela 2). As espécies muito frequentes são retratadas na literatura como produtoras de cianotoxinas (CHORUS \& BARTRAM, 1999). O predomínio das 
cianobactérias em reservatórios tropicais eutróficos deve-se a um conjunto de fatores, como elevadas temperaturas, baixa precipitação, $\mathrm{pH}$ alcalino e altas concentrações de nutrientes, principalmente N e P (FONSECA et al., 2010; SILVA et al., 2013; MOURA et al., 2007).

Tabela 1: Lista e frequência de ocorrência dos taxa de cianobactérias identificados no reservatório de Jucazinho.

\begin{tabular}{|c|c|c|c|c|c|}
\hline \multirow[b]{2}{*}{ Taxa identificados } & \multicolumn{5}{|c|}{ Reservatório de Jucazinho } \\
\hline & $\begin{array}{l}\text { set } \\
/ 14\end{array}$ & $\begin{array}{l}\text { out } \\
/ 14\end{array}$ & $\begin{array}{l}\text { nov } \\
/ 14\end{array}$ & $\begin{array}{l}\text { dez } \\
/ 14\end{array}$ & freq. (\%) \\
\hline \multicolumn{6}{|l|}{ OSCILLATORIALES } \\
\hline Geitlerinema amphibium (Greville ex Gomont) Anagnostidis 1989 & $x$ & $x$ & $x$ & $x$ & MF-100 \\
\hline Microcystis sp. Kützing ex Lemmermann 1907 & & $x$ & $x$ & $\mathrm{x}$ & MF-75 \\
\hline Planktothrix sp. Anagnostidis \& Komárek 1988 & $\mathrm{x}$ & & & $\mathrm{x}$ & $\mathrm{F}-50$ \\
\hline Pseudoanabaena sp. Lauterborn 1915 & & & $x$ & & PF-25 \\
\hline CHROOCOCCALES & & & & & \\
\hline Synechocystis sp. Sauvageau 1892 & $x$ & & & & PF-25 \\
\hline NOSTOCALES & & & & & \\
\hline Raphidiopsis curvata F.E Fritsch \& M.F. Rich 1929 & & $x$ & $x$ & $x$ & MF-75 \\
\hline Raphidiopsis mediterranea Skuja 1937 & $x$ & $x$ & $x$ & $x$ & MF-100 \\
\hline $\begin{array}{l}\text { Sphaerospermopsis aphanizomenoides (Forti) Zapomelová, } \\
\text { Jezberová, Hrouzek, Hisem, Reháková \& Komárková } 2010\end{array}$ & & & $x$ & $x$ & $F-50$ \\
\hline
\end{tabular}

MF: muito frequente; F: frequente; PF: pouco frequente.

Tabela 2: Lista e frequência de ocorrência dos taxa de cianobactérias identificados no reservatório de Carpina.

\begin{tabular}{|c|c|c|c|c|c|}
\hline \multirow[b]{2}{*}{ Taxa identificados } & \multicolumn{5}{|c|}{ Reservatório de Carpina } \\
\hline & $\begin{array}{l}\text { set } \\
/ 14\end{array}$ & $\begin{array}{l}\text { out } \\
/ 14\end{array}$ & $\begin{array}{l}\text { nov } \\
/ 14\end{array}$ & $\begin{array}{l}\text { dez } \\
/ 14\end{array}$ & freq. (\%) \\
\hline \multicolumn{6}{|l|}{ OSCILLATORIALES } \\
\hline Geitlerinema amphibium (Greville ex Gomont) Anagnostidis 1989 & $\mathrm{x}$ & $\mathrm{x}$ & $\mathrm{x}$ & $\mathrm{x}$ & MF-100 \\
\hline Planktothrix sp. Anagnostidis \& Komárek 1988 & $\mathrm{X}$ & $x$ & $x$ & $x$ & MF-100 \\
\hline Pseudoanabaena sp. Lauterborn 1915 & $\mathrm{x}$ & $\mathrm{x}$ & $\mathrm{x}$ & $\mathrm{x}$ & MF-100 \\
\hline \multicolumn{6}{|l|}{ CHROOCOCCALES } \\
\hline Aphanocapsa sp. C.Nägeli, 1849 & $\mathrm{x}$ & & & & PF-25 \\
\hline Merismopedia sp. Meyen 1839 & & & $\mathrm{x}$ & & PF-25 \\
\hline Synechocystis sp. Sauvageau 1892 & & $\mathrm{x}$ & & & PF-25 \\
\hline NOSTOCALES & & & & & \\
\hline $\begin{array}{l}\text { Cylindrospermopsis raciborskii (Woloszynska) Seenayya et Subba } \\
\text { Raju } 1972\end{array}$ & $\mathrm{X}$ & $\mathrm{X}$ & $\mathrm{x}$ & $\mathrm{x}$ & MF-100 \\
\hline Raphidiopsis curvata F.E Fritsch \& M.F. Rich 1929 & $\mathrm{X}$ & & $\mathrm{x}$ & & $\mathrm{F}-50$ \\
\hline Raphidiopsis mediterranea Skuja 1937 & $\mathrm{x}$ & $\mathrm{x}$ & $\mathrm{x}$ & $\mathrm{x}$ & MF-100 \\
\hline $\begin{array}{l}\text { Sphaerospermopsis aphanizomenoides (Forti) Zapomelová, } \\
\text { Jezberová, Hrouzek, Hisem, Reháková \& Komárková } 2010\end{array}$ & $\mathrm{x}$ & $\mathrm{x}$ & $\mathrm{x}$ & $\mathrm{x}$ & MF-100 \\
\hline
\end{tabular}

MF: muito frequente; F: frequente; PF: pouco frequente. 
A densidade de cianobactérias nos reservatórios de Jucazinho e Carpina durante o período estudado, apresentou uma variação de 639 a 2.640 .634 cél. $\mathrm{mL}^{-1}$ e 495.332 a 965.711 cél.mL , respectivamente (Figura 4). Durante este período foi observada uma tendência gradativa de crescimento da densidade, estabelecida a partir das amostragens de setembro, apresentando o maior pico no mês de novembro no reservatório de Jucazinho e no mês de dezembro no reservatório de Carpina, correspondendo aos períodos de menor precipitação nos mananciais. Este modelo de crescimento é bastante comum em reservatórios eutróficos da região nordeste, e também foram descritos nos trabalhos de Gomes (2003) e Aragão et al., (2007) para o reservatório de Carpina, sendo geralmente estabelecidos em função do aumento da temperatura e diminuição das precipitações.

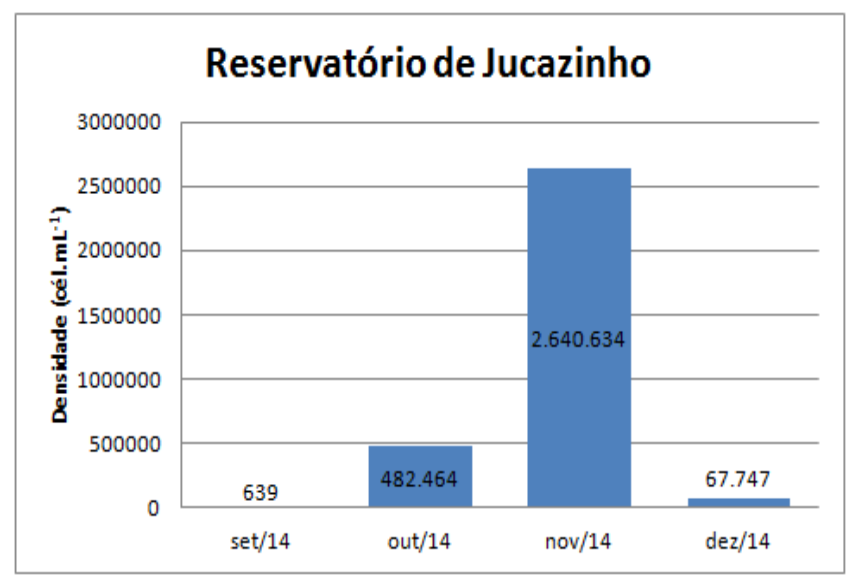

a)

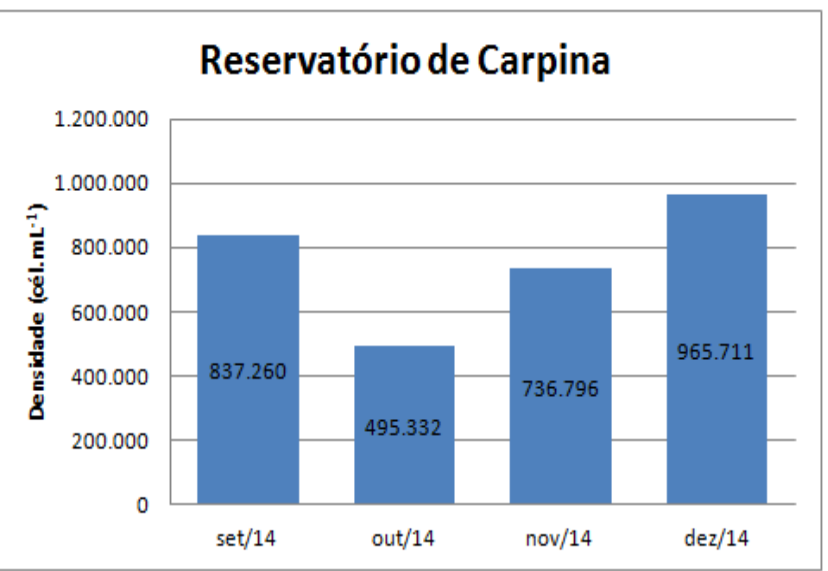

b)

Figura 4: Densidade de cianobactérias - a) reservatório de Jucazinho; b) reservatório de Carpina.

No presente estudo, com exceção da amostra do reservatório de Jucazinho coletada no mês de setembro/2014, foi observado densidade de cianobactérias acima de 50.000 cél. $\mathrm{mL}^{-1}$. As altas densidades de cianobactérias nos reservatórios têm como possíveis causas as práticas antrópicas deteriorantes, como o despejo de resíduos sólidos, lançamento de efluentes domésticos e industriais e assoreamento. Estes valores estão em desacordo com a resolução no 357 do CONAMA que diz respeito às densidades máximas estabelecidas para as águas doces de classe 2. Quanto à portaria MS no 2.914/2011, os resultados observados durante o período da pesquisa, implicam o monitoramento semanal de cianotoxinas, por apresentar densidades de cianobactérias superiores a 20.000 cél.mL $\mathrm{mL}^{-1}$. 


\subsection{Análise de cianotoxinas}

Com o teste ELISA, foi possível registrar que a concentração de microcistinas, cilindrospermopsina e saxitoxinas em ambos os reservatórios e em todos os períodos de coletas estiveram abaixo do valor máximo permissível determinado pela portaria MS 2.914/2011. De acordo com a portaria, concentrações de cianotoxinas menores que seus respectivos valores máximos permissíveis para água tratada, serão isentas da análise de cianotoxinas na saída da estação de tratamento de águas. A portaria MS 2.914/2011 define o limite máximo de microcistinas, cilindrospermopsina e saxitoxinas com o valor de $1 \mu \mathrm{g} / \mathrm{L}, 1 \mu \mathrm{g} / \mathrm{L}$ e $3 \mu \mathrm{g} / \mathrm{L}$, respectivamente.

As maiores concentrações de cianotoxinas no reservatório de Jucazinho e Carpina foram encontradas nos mês de outubro, conforme a tabela 3. Os coeficientes de variação para padrões: $<10 \%$, para amostras: $<15 \%$.

Tabela 3: Concentrações de cianotoxinas nos reservatórios de Jucazinho e Carpina, Pernambuco.

\begin{tabular}{l|c|c|c|c|c|c|c|c}
\hline \multirow{2}{*}{ Análise } & \multicolumn{3}{|c|}{ Reservatório de Jucazinho } & \multicolumn{4}{c}{ Reservatório de Carpina } \\
\cline { 2 - 9 } & set/14 & out/14 & nov/14 & dez/14 & set/14 & out/14 & nov/14 & dez/14 \\
\hline Microcistinas $(\mu \mathrm{g} / \mathrm{L})$ & 0,32 & 0,67 & $<\mathrm{LQ}$ & $<\mathrm{LQ}$ & 0,23 & 0,32 & $<\mathrm{LQ}$ & $<\mathrm{LQ}$ \\
Cilindrospermopsina $(\mu \mathrm{g} / \mathrm{L})$ & 0,06 & 0,26 & $<\mathrm{LQ}$ & $<\mathrm{LQ}$ & 0,08 & 0,21 & $<\mathrm{LQ}$ & $<\mathrm{LQ}$ \\
Saxitoxinas $(\mu \mathrm{g} / \mathrm{L})$ & 0,06 & 0,1 & 0,06 & 0,07 & 0,18 & 0,2 & 0,13 & 0,11 \\
\hline
\end{tabular}

<LQ: Menor que o limite de quantificação.

\section{CONCLUSÃO}

As altas densidades de cianobactérias nos reservatórios de Jucazinho e Carpina durante o período estudado são preocupantes. Estes valores estabelecem potencial de risco à saúde pública. Os "blooms" de cianobactérias em reservatórios de água destinada ao consumo humano originam muitos problemas, sendo o mais preocupante o fato de uma proporção significativa de cianobactérias produzirem uma ou mais toxinas.

A necessidade de monitoramento e controle de cianobactérias nas águas continentais brasileiras é uma necessidade atual, uma vez que os estudos têm confirmado a ocorrência de cianobactérias tóxicas em reservatórios utilizados para abastecimento público na maioria dos Estados brasileiros. O tratamento de águas com elevadas concentrações de cianobactérias, 
quando realizado de forma inadequada, pode não ser eficiente na remoção dessas toxinas ou mesmo favorecer sua liberação para massa de água.

É importante ressaltarmos a influência negativa das ações antrópicas, por exemplo, o descarte de efluentes urbanos em rios, que são os principais tributários dos reservatórios de abastecimento público, dando características importantes ao ambiente para o melhor desenvolvimento de cianobactérias e a possível liberação de cianotoxinas, sendo estas prejudiciais à saúde humana, é necessário que sejam tomadas medidas preventivas principalmente pelos responsáveis pelo monitoramento das águas.

\section{REFERÊNCIAS}

Agência Pernambucana de Águas e Clima (APAC). (2014). Boletim do clima. Recuperado de http://www.apac.pe.gov.br/arquivos_portal/boletins/Apac_Boletim_do_Clima

American Public Health Association (APHA). Standard methods for the examination of water and wastewater. 22 ed. 2012. Washington: APHA.

Andrade, P. R. G. S., Curi, W. F. \& Curi, R. C. (2002). Alocação ótima de recursos de água associada a operação integrada de reservatórios de usos múltiplos - uma avaliação alternativa para reforço do abastecimento de Recife. In: Seminário de Planejamento, projeto e operação de redes de abastecimento de água: 0 estado da arte e questões avançadas (10-13 Junho), 2002, João Pessoa-PB. CD-ROM, v. 1. p. 1-14.

Aragão, N. K. C. V., Gomes, C. T. S., Lira, G. A. S. T. \& Andrade, C. M. (2007). Estudo da comunidade fitoplanctônica no reservatório do Carpina-PE, com ênfase em Cyanobacteria. Artigo, UFPE, Rev Inst Adolfo Lutz, 66(3): p. 240-248.

Azevedo, S. M. F. O. (1998). Toxinas de cianobactérias: causas e consequências para a saúde pública. Med Online, 1(3). Recuperado de http://www. medonline. com.br/med_ed/med3/microcis.htm

Barreto, L. V., Barros, F., Bonomo, P., Rocha, F. \& Amorim, J. (2013). Eutrofização em rios brasileiros. Enciclopédia biosfera, Centro científico conhecer Goiânia, v. 9, n. 16, p. 2165-2179.

Bittencourt-Oliveira, M., Santos, V., Moura, A., Tavares, N. \& Araújo, M. (2014). Cyanobacteria, microcystins and cylindrospermopsin in public drinking supply reservoirs of Brazil. Annals of the Brazilian Academy of Sciences, v. 86, n. 1, p. 297-309. Recuperado de http://www.scielo.br/aabc

Brasil. Ministério da Saúde. Portaria no 2.914, de 12 de dezembro de 2011, a qual dispõe sobre os procedimentos de controle e de vigilância da qualidade da água para consumo humano e seu 
padrão de potabilidade. (2011). Diário oficial da União. 14 dez. seção 1, p.39. Recuperado de http://www.bvsms.saude.gov.br/bvs/saudelegis/gm/2011/prt2914_12_12_2011.

Calijuri, M. C., Alves, M. S. A. A. \& Santos, A. C. A. (2006). Cianobactérias e cianotoxinas em águas continentais. São Carlos: RiMa, 118p.

Carneiro, T. G. \& LEITE, F. (2008). Cianobactérias e suas toxinas. Rev Analytica, 32(32):36-41.

Companhia de Tecnologia de Saneamento Ambiental - CETESB. Fitoplâncton de água doce. Métodos qualitativo e quantitativo. (2005). São Paulo: Normas Técnicas CETESB.

Chen, H., Burke, J. M. \& Prepas, E. E. (2011). Cyanobacterial toxins in fresh waters. In: Nriagu JO, editor. Encyclopedia Environ Health. Philadelphia: Elsevier, p. 860-71.

Chorus, I. \& Bartram, J. (1999). Toxic cyanobacteria in water: a guide to their public health consequences, monitoring and management. New York: Ed. London and New York E \& FN Spon.

Companhia Pernambucana de Saneamento (COMPESA). Diretoria Comercial e de Atendimento. (2008). Relatório de informações comerciais. Recife-PE. ESTEVES, F.A. 1998. Fundamentos de Limnologia. 2a ed. Editora Interciência, RJ, 602p.

Di Bernardo, L., Minillo, A. \& Dantas, A. D. B. (2010). Florações de algas e de cianobactérias: suas influências na qualidade da água e nas tecnologias de tratamento. Primeira edição, Editora LdiBe, São Carlos, SP,

Dörr, F. A., Pinto, E., Soares, R. M. \& Azevedo, S. M. F. O. (2010). Microcystins in south american aquatic ecosystems: occurrence toxicity and toxicological assays. Toxicon., 56(7):1427-56. doi:10.1016/j.toxicon.2010.03.018

Figueredo, C. C. \& Giani, A. (2001). Seasonal variation in the diversity and species richness of phytoplankton in a tropical eutrophic reservoir. Hydrobiologia, v. 445, p.165-174, jan.

Fonseca, F. S., Ruvieri, V., Onaka, E. M., Santana, R. L., Scorsafava, M. A. \& Sabino, M. (2010). Influência de fatores climatológicos na ocorrência de microcistina. Rev Inst Adolfo Lutz., 69(4):461-6.

Gomes, C. T. S. (2003). Análise da variação qualiquantitativa do fitoplâncton no reservatório do Carpina - PE [Dissertação de mestrado]. Universidade Federal Rural de Pernambuco (UFRPE).

Komárek, J. \& Anagnostidis, K. (1986). Modern appoach to the classificationsystem of Cyanophytes, 2: Choococcales. Archiv fur Hydrobiologie, Suppl. 73, Algological Studies, 43. 157-226. 
Komárek, J. \& Anagnostidis, K. (1999). Cyanoprokaryota, 1. Teil: Chroococcales. In: Ettl HG, Gartner, Heynig \& D. Mollenhauer Ettl (eds): Susswasserfl ora von Mitteleuropa; Gustav Fischer, Stuttgart, 19. 1-545.

Komárek, J. \& Anagnostidis, K. (2005). Cyanoprokaryota, 2. Teil: Oscillatoriales. Subwasserfl ora von Mitteleuropa. Bridel B, Gaster G, Krienitz L, Schargerl M. (Hrs.) (19/2). Elsevier. p.759.

Maia-Barbosa, P. M., Peixoto, R. S. \& Guimarães, A. S. (2008). Zooplankton in littoral waters of a tropical lake: a revisited biodiversity. Braz. J. Biol, v. 68, n. 4 Suppl, p. 1069-1078, nov.

Mateucci, S. D. \& Colma, A. (1982). La metodología para el estudo de la vegetación. Collección de monografías científicas. Série Biologia 22 (1): 1-168.

Merel, S., Clément, M. \& Thomas, O. (2010). State of the art on cyanotoxins in water and their behaviour towards chlorine. Toxicon., 55(4):677-91. doi:10.1016/j.toxicon.2009.10.028

Ministérios da Integração Nacional. Departamento Nacional de Obras Contra as Secas (MINDNOCS). (1991). 3a Diretoria regional. Projeto básico da Barragem de Jucazinho. Estudo Hidrológico. Recife: Geogrupo, 236p.

Molica, R. \& Azevedo, S. (2009). Ecofisiologia de cianobactérias produtoras de cianotoxinas. Revista Oecologia Brasiliensis, v.13, n.2, p. 229-246.

Moura, A. N., Bittencourt-Oliveira, M. C., Dantas, E. W. \& Arruda Neto, J. D. T. (2007). Phytoplanktonic associations: a tool to understanding dominance events in a tropical Brazilian reservoir. Acta Bot Bras.,21(3):641-8. doi:10.1590/S0102-33062007000300011

Pernambuco. Secretaria de Ciências, Tecnologia e Meio Ambiente (SECTMA). PROÁGUA. (2004). Plano de Aproveitamento dos Recursos Hídricos da Região Metropolitana do Recife, Zona da Mata e Agreste Pernambucano. Ações complementares - Controle de Enchentes. Techine Engenheiros Consultores, TomoV. 54p.

Sant'Anna, C. L., Azevedo, M. T. P., Agujaro, L. F., Carvalho, M. C., Carvalho, L. R. \& Souza, R. C. R. (2006). Manual ilustrado para identificação e contagem de cianobactérias planctônicas de águas continentais brasileiras. Rio de Janeiro: Interciência.

Silva, E. M., Gomes, C. T. S., Ramos, C. P. S. \& Bricio, S. M. L. (2013). Ocorrência de cianobactérias no reservatório de Mundaú, no estado de Pernambuco, no período de janeiro de 2010 a novembro de 2011. VISA Debate,1(3):35-42. doi:10.3395/vd.v1i3.40

Tundisi, J. (2008). Recursos hídricos no futuro: problemas e soluções. Estudos avançados, v. 22, n. 68, p. 7-16.

Utermöhl, H. (1958). Zur vervollkommung der quantitativen phytoplankton metodik. Mitt Int. Rer. Theor. Argrew. Limnol. 9: 1-38. 